\title{
EXTENSIÓN DEL CONVENIO ARBITRAL A TERCEROS Y ORDEN PÚBLICO INTERNACIONAL: COMENTARIO AL AUTO DEL TSJ DEL PAÍS VASCO (SALA DE LO CIVIL Y PENAL) NO. 277/2018, DE 7 DE NOVIEMBRE DE 2018
}

\author{
EXTENSION OF THE ARBITRATION AGREEMENT TO A \\ THIRD PARTY AND INTERNATIONAL PUBLIC POLICY: \\ COMMENTARY ON THE ORDER OF THE TRIBUNAL \\ SUPERIOR DE JUSTICIA (HIGH COURT OF JUSTICE) OF \\ THE BASQUE COUNTRY (CIVIL AND CRIMINAL CHAMBER) \\ NO. 277/2018, OF NOVEMBER $7^{\mathrm{TH}}, 2018$
}

\author{
Marta Casado Abarquero* \\ Profesora contratada doctora \\ Universidad de Deusto \\ ORCID ID 0000-0002-7228-4044
}

Recibido: 18.06.2019 / Aceptado: 11.07.2019

DOI: https://doi.org/10.20318/cdt.2019.4975

\begin{abstract}
Resumen: En el presente auto el Tribunal Superior de Justicia del País Vasco analiza los presupuestos que deben concurrir para que la extensión de los efectos de un convenio arbitral a terceros no firmantes del mismo sea respetuosa con el orden público del foro. Igualmente, analiza algunos aspectos procesales previos, tales como la viabilidad de instar una solicitud de no-reconocimiento del laudo extranjero, o de solicitar el reconocimiento de un laudo parcial.

Palabras clave: convenio arbitral, consentimiento, orden público, derecho fundamental a la tutela judicial efectiva, exequátur, solicitud de no reconocimiento.

Abstract: In this ruling, the High Court of Justice of the Basque Country analyzes the conditions that must be met so that the extension of the effects of an arbitration agreement to a non-signatory third party is respectful of the public order of the forum. It also analyzes some previous procedural aspects, such as the viability of an application for the non-recognition of the foreign award, or of the request of recognition of a partial award.
\end{abstract}

Keywords: arbitration agreement, consent, public policy, fundamental right to the effective judicial protection, exequatur, application for non-recognition.

Sumario: I. Antecedentes de hecho. II. Eficacia extraterritorial de laudos arbitrales extranjero en España: Marco jurídico. II.1 En relación con el exequátur. II.2 En relación con la ejecución material. III. Solicitud de no-reconocimiento: herramienta procesal o extravagancia jurídica. IV.

"Este artículo ha sido desarrollado en el marco del Proyecto "Mecanismos de Reclamación de DDHH a nivel operativo"; DER 2017-87712-R del MINECO y FEDER 
Implicaciones del orden público en material arbitral. IV.1 La noción de orden público en arbitraje internacional. IV.2 Orden público y extensión del convenio arbitral a terceros. IV.3 Orden público y costas procesales. V. Reconocimiento del laudo parcial. VI. Valoración.

\section{Antecedentes de hecho}

1. El 29 de abril de 2003 ACERIES DE L'OUEST S.A.R.L. (en lo sucesivo, ADO) firmó un contrato con la empresa español BASCOTECNIA STEEL, S.L. por el que esta última vendía a la empresa argelina un laminador de acero en la ciudad argelina de $\mathrm{M}$ 'Sila por un precio aproximado de 30 millones de euros. Entre las obligaciones de BASCOTECNIA STEEL se incluían la construcción del laminador, la puesta en funcionamiento del mismo y la formación del personal local. Además, el contrato contenía un convenio arbitral por el que las partes acordaban someter las discrepancias relativas a la interpretación y ejecución del mismo a la Corte Internacional de Arbitraje de la Cámara de Comercio Internacional de París (en lo sucesivo, CCI). En este punto conviene resaltar que desde su constitución en el año 2003, BASCOTECNIA STEEL es una sociedad participada al 33\% por INGETEAM POWER TECHNOLOGY, S.A., INDUSTRIAL LAGUN ARTEA, S.A. y BASCOTECNIA, S.A.

2. BASCOTECNIA STEEL subcontrató parte de los trabajos con las sociedades que la participan. Concretamente: (i) BASCOTECNIA vendió a BASCOTECNIA STEEL un horno, grúas, naves, una estación de tratamientos de aguas y una enderezadora que esta última revendería a ADO como parte del laminador de acero en M Sila; (ii) INGETEAM suministró a BASCOTECNIA STEEL parte de los equipos eléctricos y programas de automatismo, así como parte de la supervisión del montaje y de la puesta en marcha de las instalaciones eléctricas destinados al cliente argelino; (iii) LAGUN ARTEAN suministró a BASCOTECNIA STEEL elementos mecánicos del laminador vendido a la empresa argelina y formó al personal local en la etapa de montaje de los equipos mecánicos y de la puesta en servicio del laminador.

Sin embargo, las subcontratistas, como personas jurídicas independientes, no tienen relación alguna con el cliente final. Es decir, ni BASCOTECNIA, ni LAGUN ARTEAN, ni INGETEAM son, ni han sido nunca, parte del contrato que ADO y BASCOTECNIA STEEL firmaron. Nunca han suscrito un convenio arbitral con ADO y nunca han percibido cantidad alguna de la entidad argelina.

Pese a esta aparente desafección contractual de las subcontratistas, se debe señalar que en el año 1993 se había creado la agrupación de interés económico BASCOTENIA EMPRESAS AGRUPADAS A.I.E., que tenía como miembros, entre otras, a INGETEAM POWER TECHNOLOGY, S.A., INDUSTRIAL LAGUN ARTEA, S.A. y BASCOTECNIA, S.A. Esta A.I.E. el 22 de febrero de 2003 había firmado con la empresa argelina un contrato para la realización de una fábrica productora de redondo para hormigón de diversos diámetros y perfiles, contrato que tras la constitución el 24 de abril de 2003 de BASCOTECNIA STEEL, S.L. fue sustituido por el contrato litigioso. Pues bien, ya el contrato inicial entre ADO y la A.I.E. contenía el mismo convenio arbitral que posteriormente se incorporaría al de 29 de abril de 2003.

3. En este contexto, el origen procesal del Auto del Tribunal Superior de Justicia de 7 de noviembre de 2018 que analizamos en este artículo se remonta a 2012, año en que ADO, amparándose en un supuesto incumplimiento del contrato de venta del laminador, interpuso una demanda arbitral ante la CCI de París por un importe de 30 millones de euros. Sin embargo, la demanda no la dirigió únicamente contra BASCOTECNIA STEEL, S.L., sino que demandó también a INGETEAM POWER TECHNOLOGY, S.A., INDUSTRIAL LAGUN ARTEA, S.A. y BASCOTECNIA, S.A., en su condición de suministradoras de BASCOTECNIA STEEL, y por la participación del 33\% que cada una de ellas ostentaba en el capital social de ésta.

4. La CCI de París se declaró competente para conocer de la demanda arbitral contra las cuatro mercantiles en virtud de la teoría de la implicación, teoría que según el derecho francés establece que el consentimiento expreso de un tercero es innecesario para que haya sumisión a arbitraje puesto que la implicación en la ejecución del contrato es suficiente para entender que existe consentimiento al convenio arbitral y renuncia a la jurisdicción ordinaria de los tribunales españoles. En este sentido, entendía que la 
implicación de las tres sociedades vascas subcontratistas y suministradoras de equipos a BASCOTECNIA STEEL era suficiente para concluir que estaban dando su consentimiento a una cláusula de arbitraje incorporada a un contrato que no habían firmado, es decir, el contrato entre BASCOTECNIA STEEL y ADO. Como consecuencia de ello, se dictaron las siguientes decisiones arbitrales: $1^{\text {a }}$ ) Laudo parcial No. 2, de 29 de septiembre de 2005, sobre desestimación de las excepciones de falta de competencia arbitral; $2^{a}$ ) Laudo parcial No. 3, de 19 de octubre de 2016 sobre exoneración de responsabilidad contractual y extracontractual, a INGETEAM POWER TECHNOLOGY, S.A., INDUSTRIAL LAGUN ARTEA, S.A. y BASCOTECNIA, S.A., por considerar que no eran parte en el contrato de 29 de abril de 2003 entre ADO y BASCOTECNIA STEEL, S.L; 3 $3^{\text {a }}$ Laudo parcial No. 4 de 13 de abril de 2017, de liquidación de costas en el que se impone a INGETEAM POWER TECHNOLOGY, S.A., INDUSTRIAL LAGUN ARTEA, S.A. y BASCOTECNIA, S.A. las costas derivadas exclusivamente de la desestimación de la excepción de falta de competencia que ellas plantearon ante el tribunal arbitral.

5. Frente a esta batería de laudos arbitrales, INGETEAM POWER TECHNOLOGY, S.A., INDUSTRIAL LAGUN ARTEA, S.A. y BASCOTECNIA, S.A. interponen ante el TSJ del País Vasco demanda de no reconocimiento de los Laudos parciales No. ${ }^{\circ} 2$ y 4 , fundando sus pretensiones en la vulneración del orden público: (i) Por falta de consentimiento arbitral (Laudos parciales No. ${ }^{\circ} 2$ y 4); (ii) Por falta de motivación (Laudo Parcial No. 4). Por su parte, ADO plantea demanda reconvencional frente a INGETEAM POWER TECHNOLOGY, S.A., INDUSTRIAL LAGUN ARTEA, S.A. y BASCOTECNIA, S.A., en relación con el Laudo parcial No. 4, de imposición de costas.

\section{Eficacia extraterritorial de laudos arbitrales extranjero en España: Marco jurídico}

\section{II.1. En relación con el exequátur}

6. La determinación de los efectos jurídicos de los laudos extranjeros en nuestro país es una cuestión regulada por el Convenio de Nueva York de 10 de junio de 1958, sobre reconocimiento y ejecución de las sentencias arbitrales extranjera (en lo sucesivo, "CNY 1958") ${ }^{1}$, en vigor en nuestro país desde el 10 de agosto de 1977. Así lo dispone el artículo 46.2 de la Ley 60/2003, de 23 de diciembre, de Arbitraje (en lo sucesivo, "LA"), según el cual "El exequátur de laudos extranjeros, se regirá por el Convenio sobre reconocimiento y ejecución de las sentencias arbitrales extranjeras, hecho en Nueva York, el 10 de junio de 1958, sin perjuicio de lo dispuesto en otros convenios internacionales más favorables a su concesión, y se sustanciará según el procedimiento establecido en el ordenamiento procesal civil para el de sentencias dictadas por tribunales extranjeros".

Este convenio internacional tiene carácter erga omnes, es decir, es aplicable al reconocimiento y ejecución de cualquier laudo arbitral extranjero, sin limitar su alcance a arbitrajes vinculados a otros Estados parte en el convenio, puesto que España no hizo uso de la denominada "reserva de reciprocidad" del artículo I.3 CNY 1958². Por ello, el CNY 1958 es la norma general en el sistema español de eficacia extraterritorial de laudos arbitrales procedentes de otros estados.

7. No obstante su alcance general, tanto el Convenio de Nueva York como la Ley de Arbitraje consagran el llamado "principio de mayor favorabilidad". El artículo 46.2 LA prevé la aplicación del Convenio de Nueva York "... sin perjuicio de lo dispuesto en otros convenios internacionales más favorables a la concesión del exequátur...”. Por su parte, el Artículo VII del Convenio de Nueva York prevé que "Las disposiciones de la presente Convención no afectarán la validez de los acuerdos multilaterales

\footnotetext{
${ }^{1}$ Instrumento de Adhesión de España al Convenio sobre reconocimiento y ejecución de sentencias arbitrales extranjeras, hecho en Nueva York el 10 de junio de 1958. BOE núm. 164, de 11 de julio de 1977.

2 Según el artículo I.3, "En el momento de firmar o de ratificar la presente Convención, de adherirse a ella o de hacer la notificación de su extensión prevista en el artículo X, todo Estado podrá, a base de reciprocidad, declarar que aplicará la presente Convención al reconocimiento y a la ejecución de las sentencias arbitrales dictadas en el territorio de otro Estado Contratante únicamente (...)”. La situación actual del Convenio se puede conocer a través de la siguiente página web: https:// treaties.un.org/pages/ViewDetails.aspx?src=TREATY\&mtdsg_no=XXII-1\&chapter=22\&lang=en
} 
o bilaterales relativos al reconocimiento y la ejecución de las sentencias arbitrales concertados por los Estados contratantes ni privará a ninguna de las partes interesadas de cualquier derecho que pudiera tener a hacer valer una sentencia arbitral en la forma y medida admitidas por la legislación o los tratados del país donde dicha sentencia se invoque”. De esta forma, ambos instrumentos jurídicos resuelven los problemas de concurrencia normativa que pudieran surgir entre el Convenio de Nueva York y otros convenios internacionales o, incluso, entre el Convenio de Nueva York y el propio Derecho interno en materia de exequatur de laudos extranjeros ${ }^{3}$.

8. En relación con los aspectos procesales, la tramitación del exequatur de resoluciones arbitrales extranjeras se rige por el artículo IV CNY 1958, si bien en aquellas cuestiones no reguladas por éste, el propio artículo III CNY 1958 remite a las "normas de procedimiento vigentes en el territorio donde la sentencia sea invocada”. En nuestro caso, tal remisión lo es a los artículos 41 a 61 de la Ley 29/2015, de 30 de julio, de cooperación jurídica internacional en materia civil (en lo sucesivo, "LCJIMC"). Y ello porque, aunque la Ley de Arbitraje prevalece sobre ésta en virtud del principio de especialidad ${ }^{4}$, en su artículo 46.2 LA afirma que "El exequátur de laudos extranjeros (...) se sustanciará según el procedimiento establecido en el ordenamiento procesal civil para el de sentencias dictadas por tribunales extranjeros".

Además, otras normas procesales de nuestro ordenamiento jurídico regulan aspectos tales como la competencia objetiva y funcional para la tramitación de los expedientes de exequatur de laudos arbitrales extranjeros. Los artículos 73.1.c) LOPJ y 8.6 LA atribuye el conocimiento de los mismos a la Sala de lo Civil y Penal del Tribunal Superior de Justicia de la Comunidad Autónoma del domicilio o residencia de la parte frente a la que se solicita el reconocimiento o, subsidiariamente, del lugar de ejecución o donde la resolución haya de surtir efecto.

\section{II.2. En relación con la ejecución material}

9. En todo caso, ni el Convenio de Nueva York ni la Ley de Arbitraje regulan la ejecución material de los laudos extranjeros, cuestión que según el artículo 8.6 LA in fine queda sujeta a las normas españolas de producción interna ("Para la ejecución de laudos o resoluciones arbitrales extranjeros será competente el Juzgado de Primera Instancia con arreglo a los mismos criterios").

10. En la resolución analizada ninguna de las partes parece haber instado la ejecución material del laudo, sino que se han limitado a solicitar la declaración de ejecutividad o no-ejecutividad del laudo dictado por la CCI de París. En cualquier caso, conviene resaltar que aunque el artículo 54.1 LCJIMC admite que la demanda de exequatur y la solicitud de ejecución puedan acumularse en un mismo escrito, ésta no parece una opción factible cuando de laudos arbitrales se trata. Nótese que mientras la competencia funcional para la homologación del laudo está atribuida a las Salas de lo Civil y Penal de los Tribunales Superiores de Justicia, la ejecución material del mismo compete a los Juzgados de Primera Instancia de conformidad con los artículos 85.5 LOPJ y 8.6 LA. Y para que la acumulación esté legalmente permitida, el artículo 73.1.1 ${ }^{\circ}$ LEC exige que el Tribunal que debe entender de la acción principal (en nuestro caso, de la demanda de exequatur) posea jurisdicción y competencia por razón de la materia para conocer de la acumulada (en nuestro caso, de la acción ejecutiva), presupuestos que no concurren en este caso.

\footnotetext{
${ }^{3}$ En este sentido, F. J. Garcimartín Alférez / S. SÁnchez Fernández, "Sobre el reconocimiento en España de laudos arbitrales extranjeros anulados o suspendidos en el Estado de origen”, Cuadernos de Derecho Transnacional, Vol. 8, No 1, 2016, pp. 112-113

${ }^{4}$ En relación con la jerarquía de fuentes aplicables en el ámbito de la cooperación jurídica en materia civil, el artículo 2 LCJIMC dispone que "La cooperación jurídica internacional en materia civil y mercantil, se rige por: a) Las normas de la Unión Europea y los tratados internacionales en los que España sea parte; b) Las normas especiales del Derecho interno; c) Subsidiariamente, por la presente ley". Y en la Disposición Adicional Primera e) confiere a la Ley de Arbitraje la consideración de norma especial en materia de cooperación jurídica internacional en materia civil y mercantil.
} 


\section{Solicitud de no-reconocimiento: herramienta procesal o extravagancia jurídica}

11. La delimitación del marco jurídico aplicable en España para atribuir eficacia extraterritorial a las resoluciones arbitrales dictadas fuera de nuestro país es esencial para comprender y resolver la solución dada por el TSJ del País Vasco a las pretensiones de las demandantes de solicitar el no-reconocimiento de los Laudos No. 2 y 4.

12. Como es sabido, mediante el instrumento del reconocimiento se solicita la homologación de una resolución extrajera, dotándola de todos los efectos procesales que le son propios salvo el efecto ejecutivo (es decir, se le dota del efecto constitutivo, del efecto tipicidad y del efecto de cosa juzgada material $\left.{ }^{5}\right)$. Mediante el instrumento del exequatur se convierte a una resolución extranjera en título ejecutivo, de forma que pueda desplegar eficacia ejecutiva en nuestro país como un título ejecutivo cualquiera. Ésta es la tradicional distinción entre reconocimiento y exequatur que no siempre ha sido correctamente entendida por nuestros tribunales, ni por nuestro legislador. La peculiaridad de la resolución analizada radica en que el tribunal debe resolver sobre la solicitud de no-reconocimiento planteada por INGETEAM POWER TECHNOLOGY, S.A., INDUSTRIAL LAGUN ARTEA, S.A. y BASCOTECNIA, S.A. Las demandadas en el procedimiento arbitral recurren de esta forma a una herramienta procesal bastante desconocida en nuestro sistema de eficacia extraterritorial de decisiones. Y lo hacen para conseguir un blindaje jurídico frente $\mathrm{ADO}$, anticipándose a una eventual demanda de reconocimiento por parte de la empresa argelina y adelantando, a través de un procedimiento con sustantividad propia, los motivos de oposición al mismo. Pretenden con ello, en definitiva, conseguir la estabilidad jurídica necesaria para el desarrollo de su actividad económica y comercial.

13. El TSJ del País Vasco llega a la solución correcta al admitir la posibilidad de instar el noreconocimiento, pero prescinde de un argumento legal de entidad que hubiera contribuido a reforzar su posición jurídica frente a esta cuestión. Acertadamente, en la resolución analizada el tribunal manifiesta que "la situación jurídica de gravamen en que se encuentran las demandantes (interés legítimo) es digna de protección y justifica la iniciativa de solicitar una protección anticipada de un derecho que se cree conculcado, mediante una formulación directa apoyándose en las causales de denegación, pues la postura de mera resistencia u oposición a la demanda de reconocimiento, no garantizaría la protección de unos intereses que, por ser legítimos, no estarían suficientemente tutelados si se hiciera depender su defensa, únicamente, de la conducta adoptada por la contraparte". En definitiva, entiende que la solicitud de no-reconocimiento es una pretensión legítima que debe ser acogida puesto que el Convenio de Nueva York de 1958 “(...) no impone el reconocimiento y prevé la posibilidad de denegarlo cuando se cumplan las causales de denegación, y, no prohíbe la solicitud de no reconocimiento del laudo extranjero".

14. Sin embargo, no justifica la viabilidad técnica de la solicitud en el artículo 42.2 LCJIMC, precepto que expresamente introduce en nuestro ordenamiento jurídico la posibilidad de instar el noreconocimiento de una resolución extranjera (en el contexto de la regulación del procedimiento de exequatur, el artículo 42.2 LCJIMC dispone que "El mismo procedimiento se podrá utilizar para declarar que una resolución extranjera no es susceptible de reconocimiento en España por incurrir en alguna de las causas de denegación previstas en el artículo 46").

El TSJ del País Vasco entiende que el artículo 42 LCJIMC no es de aplicación al caso puesto que la remisión efectuada por el artículo 46.2 LA y III CNY 1958 lo es a las normas internas que regulan el procedimiento judicial de exequatur. Esto es, exclusivamente a los artículos 52 a 55 LCJIMC, artículos que integran el Capítulo IV "Del procedimiento judicial de exequátur”. Sin embargo, y es aquí donde en nuestra opinión radica el error, olvida que este Capítulo IV de la LCJIMC se integra en el Título V, relativo al "Reconocimiento y ejecución de resoluciones judiciales y documentos públicos extranjeros, del procedimiento de exequátur y de la inscripción en Registros públicos", y que este Título V comienza con

${ }^{5}$ A. L. Calvo Caravaca, J. Carrascosa González, Derecho Internacional Privado, $18^{\mathrm{a}}$ ed., Ed. Comares, Granada, 2018, vol. I, pp. 383 y 384 . 
el Capítulo I (artículos 41 a 43), sobre "Disposiciones Generales" aplicables al resto de capítulos del mis$\mathrm{mo}^{6}$. Por lo tanto, este artículo 42 LCJIMC es plenamente aplicable para resolver la cuestión de la viabilidad técnica de una solicitud de no-reconocimiento de la resolución arbitral dictada por la CCI de París?

15. En todo caso, la resolución analizada resuelve con acierto la duda que la solicitud negativa de reconocimiento plantea en un contexto armonizado. De esta forma, aunque el Convenio de Nueva York de 1958 sobre el reconocimiento y la ejecución de las sentencias arbitrales extranjeras no reconoce expresamente tal posibilidad, no parece que la misma contravenga su principio inspirador, favorable al reconocimiento y ejecución de laudos arbitrales extranjeros y cuyo fundamento se encuentra en la presunción de regularidad, validez y eficacia del convenio de arbitraje, y también en la presunción de la regularidad y eficacia del laudo arbitral.

16. Esta misma afirmación pudiera hacerse también extensible a los reglamentos comunitarios en materia de cooperación judicial en material civil y mercantil, liderados todos ellos por el Reglamento 1215/2012 del Parlamento Europeo y del Consejo, de 12 de diciembre de 2012, relativo a la competencia judicial, el reconocimiento y la ejecución de resoluciones judiciales en materia civil y mercantil ${ }^{8}$. La solicitud de no-reconocimiento no parece menoscabar la eficacia extraterritorial de una resolución dictada por los tribunales de un Estado miembro. El perjudicado por la misma podría solicitar la declaración negativa de reconocimiento, anticipando así el análisis de la resolución judicial extranjera y todo ello sin merma alguna de la eficacia extraterritorial de la misma puesto que el resultado del control de las causas de denegación sería el mismo ${ }^{9}$. Dicho en otros términos, con esta herramienta jurídica se anticiparía el análisis de una resolución judicial dictada por los tribunales de otro estado miembro, de forma que la iniciativa procesal del reconocimiento no correspondería en exclusiva al acreedor o beneficiado por la resolución cuya eficacia extraterritorial se quiere hacer valer. En definitiva, la seguridad jurídica y estabilidad de las relaciones jurídico-privadas se verían reforzadas sin menoscabo alguno de la libre circulación de sentencias que inspira el sistema de reconocimiento y ejecución de resoluciones judiciales en el seno de la Unión Europea.

17. Sin embargo, no debemos obviar que esta tesis también tiene lagunas puesto que el único reglamento comunitario que alude expresamente a la solicitud de no-reconocimiento es el Reglamento (CE) $n^{\circ}$ 2201/2003 del Consejo, de 27 de noviembre de 2003, relativo a la competencia, el reconocimiento y la ejecución de resoluciones judiciales en materia matrimonial y de responsabilidad parental, por el que se deroga el Reglamento (CE) $\mathrm{n}^{0} 1347 / 2000^{10}$. De ello se infiere que esta solicitud negativa de reconocimiento no es un instrumento jurídico desconocido para el legislador comunitario por lo que el silencio que el resto de instrumentos comunitarios en la materia guardan podría interpretarse como un rechazo implícito del mismo ${ }^{11}$.

${ }^{6}$ El procedimiento de exequatur regulado por la LCJIMC no sólo sirve para autorizar la ejecución stricto sensu de una resolución judicial extranjero, sino también para declarar a título principal que la misma es reconocida (art. 42.1 LCJIMC), o para declarar que no es susceptible de reconocimiento en nuestro país (art.42.2 LCJIMC). En este sentido, F. GASCÓN INCHAUSTI, "Reconocimiento y ejecución de resoluciones judiciales extranjeras en la Ley de Cooperación Jurídica Internacional en Materia Civil", Cuadernos de Derecho Transnacional, Vol. 7, No 2, 2015, p. 160.

${ }^{7}$ Sobre los aspectos procesales de la solicitud de no-reconocimiento, vid. F. Garau Sobrino, "Artículo 42. Procedimiento de exequatur", en F.P. Méndez, G. Palao Moreno (Dir.): Comentarios a la Ley de cooperación jurídica internacional en materia civil, Tirant lo Blanch-Registradores de España, Valencia 2017, p.489-490.

${ }^{8}$ DOUE L 351, de 20 diciembre 2012.

${ }^{9}$ En cualquier caso, no se trata de una solución pacífica en los ordenamientos europeos. Los tribunales griegos, por ejemplo, se han mostrado contrarios a admitir una solicitud de no-reconocimiento de una orden inglesa en Grecia en aplicación del art. 39 del Reglamento Bruselas I, por considerarla contraria a la libre circulación de resoluciones judiciales en que se inspira la norma comunitaria. En este sentido, A. Ancimos, "Reconocimiento y ejecución de sentencias extranjeras según el reglamento Bruselas I en Grecia", Anuario español de derecho internacional privado (AEDIPR), Vol. 13, 2013, p. 593.

${ }^{10}$ DOUE L 338, de 23 de diciembre 2003. Este reglamento, en su artículo 21.3 establece que "cualquiera de las partes interesadas podrá, de conformidad con los procedimientos previstos en la sección 2 , solicitar que se resuelva sobre el reconocimiento o no reconocimiento de una resolución".

${ }^{11}$ El TJUE no se han pronunciado aún sobre este extremo. Sí lo ha hecho en relación con la solicitud de no reconocimiento 


\section{Implicaciones del orden público en material arbitral}

18. El Convenio de Nueva York de 1958 está inspirado por un principio favorable al reconocimiento y ejecución de la sentencia arbitral extranjera, así como por la prohibición de revisión en cuanto al fondo del asunto. Ello se infiere de la exigencia ineludible a los Estados contratantes de reconocer la autoridad de la sentencia arbitral y conceder su ejecución, que tan sólo podrá denegarse por motivos expresamente tasados. La Convención especifica seis razones por las que se puede denegar el reconocimiento y la ejecución de una sentencia arbitral a instancia de la parte contra la cual es invocada. Tales razones son: (i) La incapacidad de las partes; (ii) Inexistencia o invalidez del acuerdo de arbitraje; (iii) Inobservancia de los derechos de defensa en el procedimiento arbitral; (iv) Incongruencia del laudo arbitral; (v) Constitución irregular del Tribunal arbitral o irregularidades del procedimiento arbitral; (vi) Y la anulación o suspensión de la sentencia arbitral en el país en el cual, o conforme a la ley del cual, se ha dictado $^{12}$. La Convención específica, además, otras dos razones en virtud de las cuales un tribunal puede, de oficio, negarse a reconocer y ejecutar una sentencia. Estas razones aluden a materias no susceptibles de arbitraje y a que el reconocimiento o ejecución del laudo arbitral sean contrarios al orden público del Estado requerido ${ }^{13}$.

19. En este marco legal, el orden público es el único motivo que entraña en sentido estricto un control de fondo de la decisión arbitral, siendo la única y exclusiva excepción a la regla de la prohibición de revisión del fondo del laudo arbitral. Por este motivo, el recurso a la noción de orden público suele ser el subterfugio procesal utilizado para convertir los procedimientos de reconocimiento y ejecución de un laudo en una suerte de segunda instancia. Consciente de esta realidad, el TSJ del País Vasco acertadamente afirma en su Fundamento de Derecho Cuarto, apartado 4.1.2., que "resulta razonable sostener que la noción de orden público sólo debe utilizarse para evitar el reconocimiento de un laudo que contradiga de forma manifiesta principios fundamentales, no aquéllos otros que, por muy discutible que pueda llegar a ser, no chocan o conculcan los principios nucleares de nuestra convivencia. Debe ser un control ejercitado a partir, como con anterioridad señalábamos, de una concepción limitada del orden público y en un contexto donde el respeto y sincero reconocimiento de la autonomía del arbitraje internacional no conlleve sacrificar los principios fundamentales de cada ordenamiento jurídico en particular ni de la comunidad internacional en general". Así las cosas, es preciso determinar con la mayor claridad y precisión posible el alcance de la noción de orden público a la que alude el artículo V.2 CNY 1958.

\section{IV.1 La noción de orden público en arbitraje internacional}

20. La excepción del orden público se encuentra reconocida en diferentes instrumentos. Por ejemplo, el artículo V.2.b) CNY 1958, dispone que “(...) se podrá denegar el reconocimiento y la ejecución de una sentencia arbitral si la autoridad competente del país en que se pide el reconocimiento y la ejecución, comprueba: (...); b) Que el reconocimiento o la ejecución de la sentencia serían contrarios al orden público de ese país". Por su parte, aunque la Ley de Arbitraje no resulta de aplicación al caso puesto que en este punto resulta desplazada por el Convenio de Nueva York, contiene una precisión similar en su artículo 41.1 f). Además, la excepción de orden público no es exclusiva del arbitraje comercial internacional, consagrándose también como motivo de oposición al reconocimiento de la efica-

en el marco de una decisión de restitución de menor (STJUE de 11 de julio 2008, C-195/08, Rinau, ECLI:EU:C:2008:406). Entre los objetivos que según el TJUE puede perseguir una solicitud de no reconocimiento estarían aquellos "ya sean de orden material, en particular los relativos al interés superior del menor o a la estabilidad y tranquilidad de la familia, ya sean de naturaleza procedimental". Sobre el análisis esta resolución y la apuesta del Tribunal por el favor executionis, vid. A. EsPINIELLA MENÉNDEZ, "Solicitud de no reconocimiento de una decisión de restitución-Admisibilidad de alegaciones por la parte beneficiada por el reconocimiento: Sentencia del Tribunal de Justicia de las Comunidades Europeas (Sala Tercera), de 11 de julio de 2008", Revista española de derecho internacional (REDI), Vol. 60, 2008, p. 601-602.

${ }^{12}$ Cfr. Art. V.1 CNY 1958.

${ }^{13}$ Cfr. Art. V.2 CNY 1958. 
cia extraterritorial de resoluciones judicial en los reglamentos comunitarios sobre cooperación judicial internacional en materia civil y mercantil ${ }^{14}$.

21. Pese a su general admisibilidad como motivo de impugnación, el concepto de orden público es uno de los más difíciles de ser explicados por la doctrina jurídica ${ }^{15}$. En su carácter vago e imprecisión se ha visto una fuente de peligro, hasta el punto de que algunos reglamentos comunitarios relativos a la eficacia extraterritorial de resoluciones judiciales dentro de la Unión Europea han optado abiertamente por su supresión ${ }^{16}$. Se caracteriza por la tradicional dificultad de su definición o concreción, así como por su carácter evolutivo y mudable en el espacio y en el tiempo ${ }^{17}$, careciendo de un contenido autónomo y uniforme $^{18}$. Por su parte, como acertadamente señala la resolución analizada, el TJUE al interpretar la noción de orden público utilizada por el Convenio de Bruselas de 1968 y sus descendientes legislativos ha matizado que no le corresponde a él definir el contenido del concepto de orden público del Estado requerido, si bien sí puede controlar los límites dentro de los cuales los Tribunales nacionales pueden recurrir a este concepto como motivo de denegación del reconocimiento. Se trata en todo caso de un concepto estrictamente nacional y, en todo caso, de aplicación excepcional respecto del cual el TJUE únicamente ha llegado a definir qué no es, precisando que se trata de una violación manifiesta de una norma considerada esencial o de un derecho reconocido como fundamental por el ordenamiento del Estado receptor ${ }^{19}$.

22. En cualquier caso, el Tribunal Constitucional en su sentencia 43/1986, de 15 de abril ${ }^{20}$, puso de manifiesto la vertiente constitucional del orden público y subrayó que "El concepto de orden público ha adquirido una nueva dimensión a partir de la vigencia de la Constitución de 1978. Aunque los derechos fundamentales y libertades públicas que la Constitución garantiza sólo alcanzan plena eficacia allí donde rige el ejercicio de la soberanía española, nuestras autoridades públicas, incluidos los Jueces y Tribunales, no pueden reconocer ni recibir resoluciones dictadas por autoridades extranjeras que supongan vulneración de los derechos fundamentales y libertades públicas garantizados constitucionalmente a los españoles o, en su caso, a los españoles y extranjeros" (FJ 4) ${ }^{21}$.

${ }^{14}$ Sobre el orden público y el arbitraje internacional, G. JimÉnez Blanco, "El orden público como excepción al reconocimiento y ejecución de laudos extranjeros", Revista del Club España del Arbitraje, 2019, pp. 73-95.

${ }^{15}$ L. LÓPEZ ZAMORA, "Comentarios sobre el orden público internacional en sede arbitral internacional, su funcionalidad y su interrelación con el Derecho Internacional Público”, Cuadernos de Derecho Transnacional, Vol. 10, No 2, 2018 , p. 517.

${ }^{16}$ Así, por ejemplo, el Reglamento 861/2007, de 11 de julio de 2007, por el que se establece un proceso europeo de escasa cuantía (DOUE L 199, de 31 de julio 2007), Reglamento 1896/2006, de 12 de diciembre de 2006, por el que se establece un proceso monitorio europeo (DOUE L 399, de 30 de diciembre 2006) o el Reglamento 805/2004, de 21 de abril de 2004, por el que se establece un título ejecutivo europeo para créditos no impugnados (DOUE L 143, de 30 de abril 2004).

${ }^{17}$ Se ha hablado, así, de su vertiente política, su vertiente moral, su vertiente social, su vertiente económica; Se ha aludido igualmente a un orden público de dirección frente a otro de protección; Se ha hablado de una dimensión de Derecho público y otra de Derecho privado; De un orden público material y un orden público procesal; De un orden público interno y un orden público internacional y, más allá de éste, incluso de un orden público transnacional. En este sentido, M. GonZALo Quiroga, Orden público y arbitraje internacional en el marco de la globalización comercial, Ed. Dykinson, Madrid, 2003, p. 57.

${ }^{18}$ El Comité de Arbitraje Comercial Internacional de la Asociación de Derecho Internacional (Committee on International Commercial Arbitration of the International Law Association) ha acometido la tarea de elaborar un proponer unos criterios comunes que permitan definir con una cierta uniformidad esa cláusula general del orden público como motivo de denegación del reconocimiento de laudos arbitrales extranjeros. El resultado ha sido un conjunto de recomendaciones que tienen por objeto facilitar una aplicación lo más uniforme posible de la figura del orden público como motivo de denegación del reconocimiento de laudos extranjeros y que conforman el "Final Report on Public Policy as a Bar to Enforcement of International Arbitration Awards", publicado en la revista de la London Court of International Arbitration (LCIA), Arbitration International, Vol. 19, Issue 2, 2003, pp. 249-263.

${ }^{19}$ Entre otras, STJUE de 28 de marzo 2000, C-7/98, Krombach, ECLI:EU:C:2000:164; STJUE de 11 de mayo 2000, C-420/07, Renault, ECLI:EU:C:2000:225; STJUE de 28 de abril 2009, C-420/07, Apostolides, ECLI:EU:C:2009:271; STJUE de 6 de septiembre 2012, C-619/10, Trade Agency, ECLI:EU:C:2012:531; STJUE de 23 de octubre 2014, C-302/13, FlyLALLithuanian Airlines, ECLI:EU:C:2014:2319.

${ }^{20}$ ECLI:ES:TC:1986:43

${ }^{21}$ En cualquier caso, limitar el orden público al orden público constitucional es un error. En este sentido, M. VIRGOs, "El reconocimiento y ejecución de laudos arbitrales extranjeros", Spain Arbitration Review/Revista del Club Español del Arbitraje, № 5, 2009, pág. 90 . 


\section{IV.2. Orden público y extensión del convenio arbitral a terceros}

23. La resolución analizada debe resolver si el Laudo parcial No. 2, de 29 de septiembre de 2015, en el que el Tribunal arbitral rechaza las excepciones de inadmisibilidad e incompetencia y se declara competente para conocer de la demanda de ADO es contrario al orden público. En este sentido, la representación de legal de INGETEAM POWER TECHNOLOGY, S.A., INDUSTRIAL LAGUN ARTEA, S.A. y BASCOTECNIA, S.A. entiende que la extensión de los efectos del convenio arbitral a terceros no firmantes del mismo por el mero hecho de su implicación directa en la ejecución del contrato principal es contraria al orden público español puesto que no se ha verificado si hubo o no consentimiento al arbitraje, consentimiento que debe constatarse y evidenciarse a través de una voluntad efectiva, patente e inequívoca de someterse al arbitraje.

24. La Sala de lo Civil del Tribunal Supremo se ha pronunciado en reiteradas ocasiones sobre las características que debe reunir el consentimiento para poder ser reputado como tal, resaltando que "lo decisivo para la validez del convenio arbitral no es tanto la firma de las partes o la utilización de determinadas fórmulas como la prueba de la voluntad inequívoca de las partes contractuales de someter sus controversias a arbitraje, siendo destacable en este sentido cómo la jurisprudencia más reciente de esta Sala se pronuncia en contra de las "fórmulas sacramentales» como condicionantes de la validez de las cláusulas de sumisión a arbitraje"22.

25. En consonancia con la misma línea argumental, en relación con la exigencia que impone el art. IV CNY 1958 de aportar el acuerdo por escrito que contenga la cláusula compromisoria, el Tribunal Supremo ha establecido que "la ratio del precepto no ha de ser otra que la de ofrecer al Tribunal del exequatur la constancia del concierto entre las partes de acudir a la vía arbitral para solventar sus disputas en el seno de un determinado contrato, constancia que excede lo puramente formal y puede venir dada por diversas vías, siendo una de ellas, sin lugar a dudas, la propia conducta en el procedimiento de origen de las partes, acto propio que ha de causar estado en este de homologación "23.

26. Acierta el TSJ del País Vasco al poner de manifiesto la trascendencia constitucional que una interpretación elástica de la cláusula de sumisión a arbitraje puede tener sobre el derecho fundamental a la tutela judicial efectiva. Y para ello cita la sentencia 136/2010, de 3 de diciembre, en la que el Tribunal Constitucional afirma que salvo que el litigante lo haya aceptado voluntariamente, no se le puede impedir que sea precisamente un órgano judicial quien conozca de las pretensiones que formule en orden a su defensa, pues de otra manera se vulneraría su derecho a la tutela judicial efectiva, precisando que la renuncia al ejercicio de las acciones ante los tribunales mediante una sumisión al arbitraje debe ser explícita, clara, terminante e inequívoca ${ }^{24}$.

27. Igualmente aplaudido debe ser el esfuerzo que hace el TSJ del País Vasco por recordar, a lo largo de las 29 páginas del auto, las bases del debate. Esto es, no se trata tanto de examinar la validez o no de la jurisprudencia francesa sobre la teoría de la implicación, como de comprobar que de la misma se infiere la existencia de una voluntad clara e inequívoca de las partes de someter sus discrepancias al arbitraje de la $\mathrm{CCI}^{25}$.

28. Y es en este punto donde, en nuestra opinión, podemos poner el único pero a la resolución analizada puesto que el TSJ del País Vasco parece asimilar el tener conocimiento de la cláusulas arbitral y

\footnotetext{
${ }^{22}$ STS de 6 febrero 2003 (ECLI:ES:TS:2003:713). En el mismo sentido, STS de 27 junio 2017 (ECLI:ES:TS:2017:2500)

${ }^{23}$ ATS de 4 marzo 2003 (ECLI:ES:TS:2003:2447A). En el mismo sentido, entre otras ATS de 1 de diciembre 1998 (ECLI:ES:TS:1998:968A ); de 28 de marzo 2000 (ECLI:ES:TS:2000:238A); de 16 de mayo 2001 (ECLI:ES:TS:2001:2190A ) o de 12 de marzo 2002 (ECLI:ES:TS:2003:6401A).

${ }^{24}$ ECLI:ES:TC:2010:136. FJ 2.

${ }^{25}$ La teoría de la implicación ha sido una de las diferentes doctrinas empleadas para extender el alcance del convenio arbitral a terceros. Sobre las distintas teorías existentes en el panorama comparado, vid. C. BoucKaERT, R. DuPEYré, "La Participación de terceros en el arbitraje internacional”, Spain arbitration review: revista del Club Español del Arbitraje, No 9, 2010, par. 29-46.
} 
haber estado implicado en la ejecución del mismo, con el hecho de prestar consentimiento a la misma de forma clara, terminante e inequívoca. Así, el TSJ afirma que "no habiendo desacreditado las actoras tal relato factual, de ellas se extrae la misma conclusión de que las hoy actoras conocían la existencia de la cláusula arbitral, y ese conocimiento se ajusta a nuestra normativa arbitral, asi como al contenido de los derechos y garantías constitucionalmente consagrados y protegidos, por lo que no puede hablarse de vulneración de los mismos, ni, por ende, del orden público considerado en sentido internacional". Atendiendo a este razonamiento, ¿en qué contrato deberían las empresas subcontratadas haber introducido la precisión de que no se entienden vinculadas por el sometimiento a arbitraje acordado entre BASCOTECNIA STEEL y ADO?, ¿en el contrato principal, en el que no son parte?, ¿en los contratos entre BASCOTECNIA STEEL y cada una de ellas, en los que es ADO quien no es parte contractual?, ¿acaso deberían haberlo puesto de manifiesto en una suerte de acta de manifestaciones unilateral? Con estos interrogantes lo único que pretendemos poner de relieve es que con una aplicación estricta y literal de los postulados mantenidos en la parte final del Fundamento de Derecho 4.3 del auto comentado, cualquier empresa subcontratada que tenga conocimiento del contenido del contrato principal se puede ver sorprendida por una cláusula de sometimiento a arbitraje que conoce pero cuyos efectos, en principio, presume limitados a las partes que la han convenido. En este sentido, el TSJ parece olvidar la jurisprudencia del Tribunal Constitucional que él mismo cita. Nos referimos a la sentencia del Tribunal Constitucional 1/2018, de 11 de enero, en cuyo Fundamento de Jurídico Tercero afirma que "si bien la renuncia puede inferirse de la conducta de los titulares del derecho, no es lícito deducirla de una conducta no suficientemente expresiva del ánimo de renunciar"26.

\section{IV.3. Orden público y costas procesales}

29. Planteada la cuestión de si procede o no estimar la demanda de denegación de reconocimiento del Laudo parcial No. 4, relativa a la imposición por parte de la CCI de París de las costas del procedimiento a INGETEAM POWER TECHNOLOGY, S.A., INDUSTRIAL LAGUN ARTEA, S.A. y BASCOTECNIA, S.A., el TSJ del País Vasco debe analizar si ésta es contrario al orden público por manifiesta irrazonabilidad e incongruencia dado que estas mercantiles fueron exoneradas de toda responsabilidad, tanto contractual como extracontractual, respecto de la sociedad argelina. Dicho en otros términos, la cuestión que se suscita es si la imposición parcial de costas del procedimiento a la parte que ha resultado absuelta en la demanda principal es contraria al orden público español.

30. La resolución analizada resuelve correctamente la cuestión, al subrayar que según la doctrina constitucional la imposición de las costas procesales es un problema de legalidad ordinaria sin relevancia constitucional que, en principio, no provoca lesión alguna del derecho a la tutela judicial efectiva ${ }^{27}$, y que únicamente se puede ver afectada cuando la resolución judicial incurre en error patente, arbitrariedad, manifiesta irrazonabilidad o si no está motivada ${ }^{28}$. En este sentido, el Tribunal Constitucional ha manifestado que "Ello implica, en primer lugar, que la resolución ha de estar motivada, es decir, contener los elementos y razones de juicio que permitan conocer cuáles han sido los criterios jurídicos que fundamentan la decisión; y en segundo lugar, que la motivación esté fundada en Derecho, carga que no queda cumplida con la mera emisión de una declaración de voluntad en un sentido u otro, sino que debe ser consecuencia de una exégesis racional del Ordenamiento y no fruto de la arbitrariedad. Lo anterior conlleva la garantía de que el fundamento de la decisión sea la aplicación no arbitraria de las normas que se consideren adecuadas al caso, pues tanto si la aplicación de la legalidad es fruto de un error patente, como si fuere arbitraria, manifiestamente irrazonada o irrazonable no podría considerarse fundada en Derecho, dado que la aplicación de la legalidad sería tan sólo una mera apariencia. En suma, el art.

${ }^{26}$ ECLI:ES:TC:2018:1. En idénticos términos, STC 65/2009, de 9 de marzo, FJ 4 (ECLI:ES:TC:2009:65).

${ }^{27}$ SSTC 170/2002, de 30 de septiembre,FJ17(ECLI:ES:TC:2002:170); 172/2009, de 9 dejulio,FJ3 (ECLI:ES:TC:2009:172).

${ }^{28}$ Entreotras,SSTC134/1990, de 19dejulio,FJ5(ECLI:ES:TC:1990:134);190/1993, de14dejunio,FJ4(ECLI:ES:TC:1993:190); 41/1994, de 15 de febrero, FJ 2 (ECLI:ES:TC:1994:41); 191/2001, de 1 de octubre, FJ 6 (ECLI:ES:TC:2001:191); 170/2002, de 30 de septiembre, FJ 17 (ECLI:ES:TC:2002:170); 107/2006, de 3 de abril, FJ 3 (ECLI:ES:TC:2006:107); y 51/2009, de 23 de febrero, FJ 2 ( ECLI:ES:TC:2009:51). 
24 CE impone a los órganos judiciales no sólo la obligación de ofrecer una respuesta motivada a las pretensiones deducidas, sino que, además, ésta ha de tener contenido jurídico y no resultar arbitraria"29.

31. Por lo tanto, con este marco jurídico, lo único que le resta al TSJ es dilucidar si el Laudo No. 4 ha incurrido o no en error patente, arbitrariedad, manifiesta irrazonabilidad o, si la resolución carece de motivación alguna. Y tras reproducir exhaustivamente la motivación del laudo cuya denegación de reconocimiento se pretende, el TSJ del País Vasco llega acertadamente a la conclusión de que la decisión arbitral está perfectamente motivada, no adolece de arbitrariedad alguna y es el resultado de la aplicación del principio del vencimiento objetivo. La CCI de París impone a las empresas españolas las costas derivadas de la desestimación de las excepciones de inadmisibilidad e incompetencia que éstas plantearon y que fueron rechazadas en aplicación de la doctrina francesa de la implicación ${ }^{30}$. Por lo tanto, no apreciándose error patente, arbitrariedad, manifiesta irrazonabilidad o falta de motivación, concluye que el reconocimiento del Laudo parcial No. 3 de 13 de abril de 2017 no atenta contra el orden público.

\section{Reconocimiento parcial del laudo}

32. Dentro de este iter procesal, por parte de la empresa argelina se plantea reconvención instando el reconocimiento parcial del Laudo No. 4 de 13 de abril de 2017 (laudo relativo a las costas del procedimiento analizado en el apartado anterior), pero circunscribiendo el alcance del mismo a aquellos partidas relativas a la imposición de costas a las empresas españolas como consecuencia de la desestimación de sus pretensiones de inadmisibilidad y falta de competencia de la CCI de París. La empresa argelina plantea la reconvención sin haber solicitado previamente el reconocimiento del Laudo No. 2, de 29 de septiembre de 2005, laudo en el que se rechazan las excepciones de incompetencia y de inadmisibilidad y al que el Laudo No. 4 está indisolublemente unido puesto que trae causa del mismo.

33. El reconocimiento parcial implica proceder al reconocimiento de algunos de los pronunciamientos de la resolución extranjera y es algo habitual, tanto en los instrumentos europeos como en el Derecho de los países de nuestro entorno ${ }^{31}$. La LCJIMC permite solicitar, obtener o conceder el reconocimiento (artículo 49) y la ejecución parcial de una resolución extranjera (artículo 50.3). Por su parte, el artículo V.1 c) CNY 1958 también parece admitir el reconocimiento parcial de un único pronunciamiento cuando éste es divisible.

34. No obstante, para que el reconocimiento parcial sea posible es presupuesto necesario el que los diferentes pronunciamientos no estén unidos por una relación de dependencia, puesto que si unos son los antecedentes lógicos necesarios de otros no cabrá aplicar el principio de separabilidad ${ }^{32}$. Ésta es precisamente la causa por la que el auto analizado deniega el reconocimiento parcial del Laudo No. 4, puesto que el pronunciamiento sobre las costas está indisolublemente ligado al Laudo No. 2 sobre desestimación de la excepción de incompetencia planteada por INGETEAM POWER TECHNOLOGY, S.A., INDUSTRIAL LAGUN ARTEA, S.A. y BASCOTECNIA, S.A. del que trae causa ${ }^{33}$. No se puede

\footnotetext{
${ }^{29}$ SSTC 308/2006, de 23 de octubre, FJ 5 (ECLI:ES:TC:2006:308).

${ }^{30}$ Este criterio del vencimiento objetivo se ajusta, además, al criterio mantenido por el artículo 394 LEC. Sobre los diferentes sistemas en materia de costas vigentes en nuestro entorno, vid. A. VALIÑo Arcos, "Algunos aspectos relacionados con la imposición de costas en el proceso civil en el Derecho comparado", Revista Chilena de Derecho, vol. 29, 1, 2002, pp. 147-161. Según este estudio, los sistemas de imposición de costas existentes pueden quedar reconducidos a tres: Los que aplican el criterio del vencimiento (quien pierde paga todos los gastos); los que se inspiran en la causalidad (puede ser condenado en costas no sólo quien resulta derrotado sino también el vencedor del juicio que pudo evitarlo o ponerle fin y no consintió); y los que dejan al juez decidir en cada caso (incluyendo el reparto discrecional entre los litigantes de los gastos del proceso).

${ }^{31}$ Apartado VIII del Preámbulo de la LCJIMC.

32 J.J. Álvarez Rubio, “Artículo 49. Reconocimiento parcial”, en F.P. Méndez, G. Palao Moreno (Dir.): Comentarios a la Ley de cooperación jurídica internacional en materia civil, Tirant lo Blanch-Registradores de España, Valencia 2017, p.574.

${ }^{33}$ Los profesores M. Virgos Soriano y F.J. Garcimartín Alférez, vinculan la separabilidad de los pronunciaientos con la conexión interna existente entre ellos. Vid. M. Virgos Soriano y F.J. Garcimartín AlfÉrez, Derecho procesal civil internacional. Litigación internacional, CivitasThomson Reuters, Madrid 2007, 2a ed., pp. 567-570.
} 
reconocer el Laudo parcial No. 4 sin haber planteado previa o simultáneamente el reconocimiento del Laudo parcial No. 2.

\section{Valoración}

35. El auto del TSJ del País Vasco analiza el difícil equilibrio entre la extensión de los efectos del convenio arbitral a terceros inicialmente no signatarios del mismo y la tutela judicial efectiva. Desde un plano teórico, condiciona con acierto la ampliación subjetiva del alcance del convenio arbitral a la existencia de una voluntad explícita, clara, terminante e inequívoca de todas las partes en favor del arbitraje (prescindiendo de formalismos o fórmulas rituarias). Desde un punto de vista práctico, al enjuiciar la eventual compatibilidad o contrariedad del laudo arbitral con el orden público del foro pone de relieve la estrecha vinculación de éste con la obligación de la corte de arbitraje de constatar la existencia de tal voluntad, sin que el mero conocimiento de la cláusula arbitral por parte del tercero y/o su implicación en la ejecución del contrato parezca suficiente para presumir este consentimiento.

36. La solicitud de no-reconocimiento de un laudo arbitral, admitida por el artículo 42.2 LCJIMC, es compatible con el Convenio de Nueva York de 1958. Este convenio internacional no alude expresamente a la posibilidad de instar una acción declarativa negativa pero los efectos de ella son coherentes con los objetivos perseguidos por la convención. El principio favorable al reconocimiento de laudos arbitrales que la inspira no resulta menoscabado por el ejercicio de una acción de no-reconocimiento, puesto que con ella únicamente se permite a la parte perjudicada por la resolución anticipar el análisis y control de las causas de no reconocimiento, sin alterar el resultado material del mismo, favoreciendo la seguridad jurídica y la estabilidad de las relaciones comerciales. 